\title{
Unexpected Products from the Reaction of the Synthetic Cross-Linker 3,3'- Dithiobis(Sulfosuccinimidyl Propionate), DTSSP with Peptides
}

\author{
Catherine L. Swaim, Jean B. Smith, and David L. Smith \\ Department of Chemistry, University of Nebraska, Lincoln, Nebraska, USA
}

\begin{abstract}
Synthetic cross-linking reagents, such as 3,3'-dithiobis(sulfosuccinimidyl propionate), DTSSP, can react with sidechains of amino acids that are within close proximity. Identification of cross-linked residues provides insight into the folded structures of proteins. However, analysis of proteolytic digests of proteins cross-linked with commercially available DTSSP is difficult because many ions cannot be attributed to reported reactions of DTSSP. To better understand the reactivity of DTSSP, products from the reaction of DTSSP with several model peptides were analyzed by HPLC electrospray ionization mass spectrometry (ESIMS). Several products not previously reported were identified. Sources for these unexpected products were traced to reaction of DTSSP with contaminant ammonium ions in the buffer, to reaction of contaminants present in the commercial DTSSP reagent, and to reactivity of DTSSP with serine and tyrosine residues. In addition, the collision-induced-dissociation (CID) of peptides modified by DTSSP was investigated. These results showed that certain DTSSP-peptide adducts easily undergo in-source fragmentation to give additional unexpected ions. This study of the reactions of DTSSP with model peptides has revealed the major types of ions that are likely to be found in proteolytic digests of proteins cross-linked with DTSSP, thereby facilitating identification of the cross-linked residues that can provide information about the three-dimensional structures of folded proteins. (J Am Soc Mass Spectrom 2004, 15, 736-749) @ 2004 American Society for Mass Spectrometry
\end{abstract}

$\mathrm{T}$ The biological functions of proteins are determined by their three-dimensional structures. The most widely used techniques for determining these structures, X-ray crystallography and NMR, both require large amounts of protein. In addition, growth of high quality crystals may be problematic for X-raycrystallography and high resolution NMR analysis is generally limited to highly soluble proteins with molecular weights less than $30 \mathrm{kDa}$. Cross-linking residues within close proximity is another approach for obtaining three-dimensional structural information. Although the resolution of this approach is usually low, it requires little material and can be applied to sparingly soluble proteins of virtually any size. Cross-linkages may be either intramolecular or intermolecular. Intramolecular cross-linking demonstrates which regions within a protein are adjacent [1-3], while intermolecular cross-linking indicates adjacent regions of subunits in a protein assembly [4-6]. To identify cross-linked residues, proteins are digested into peptides whose identi-

Published online March 17, 2004

Address reprint requests to Dr. D. L. Smith, Department of Chemistry, University of Nebraska, Lincoln, NE 68588-0304, USA. E-mail: dsmith7@unl.edu ties are determined by mass spectrometry (MS). Specific residues joined by cross-linkages may be identified from the amino acid sequence of the peptide if the reactivity of the cross-linking reagent is known, or by collision-induced-dissociation (CID) MS/MS analyses of the cross-linked peptides. This combination of crosslinkers and mass spectrometry provides information that may lead to detailed three-dimensional structures of proteins [1].

The cross-linking reagent, DTSSP, is often used for these structural analyses [4, 7-12]. This homobifunctinal cross-linker reacts with the primary amines of lysines and the N-termini of proteins [13]. As illustrated in Figure 1, two types of products characterized by mass increases of 174 or $192 \mathrm{Da}$ are expected. Intra- or intermolecular cross-linking (+174 Da) results if two sites, which are in close proximity either within one molecule or between two molecules, react with the two ends of DTSSP. If a second site does not react with DTSSP or if one end of DTSSP hydrolyzes before reaction with the protein, peptides may be detected with a hydrolyzed adduct (+192 Da). The disulfide bond at the center of DTSSP can be used to help identify cross-linked peptides. Reduction of this disulfide bond yields the initial molecule(s) with molecular masses that 


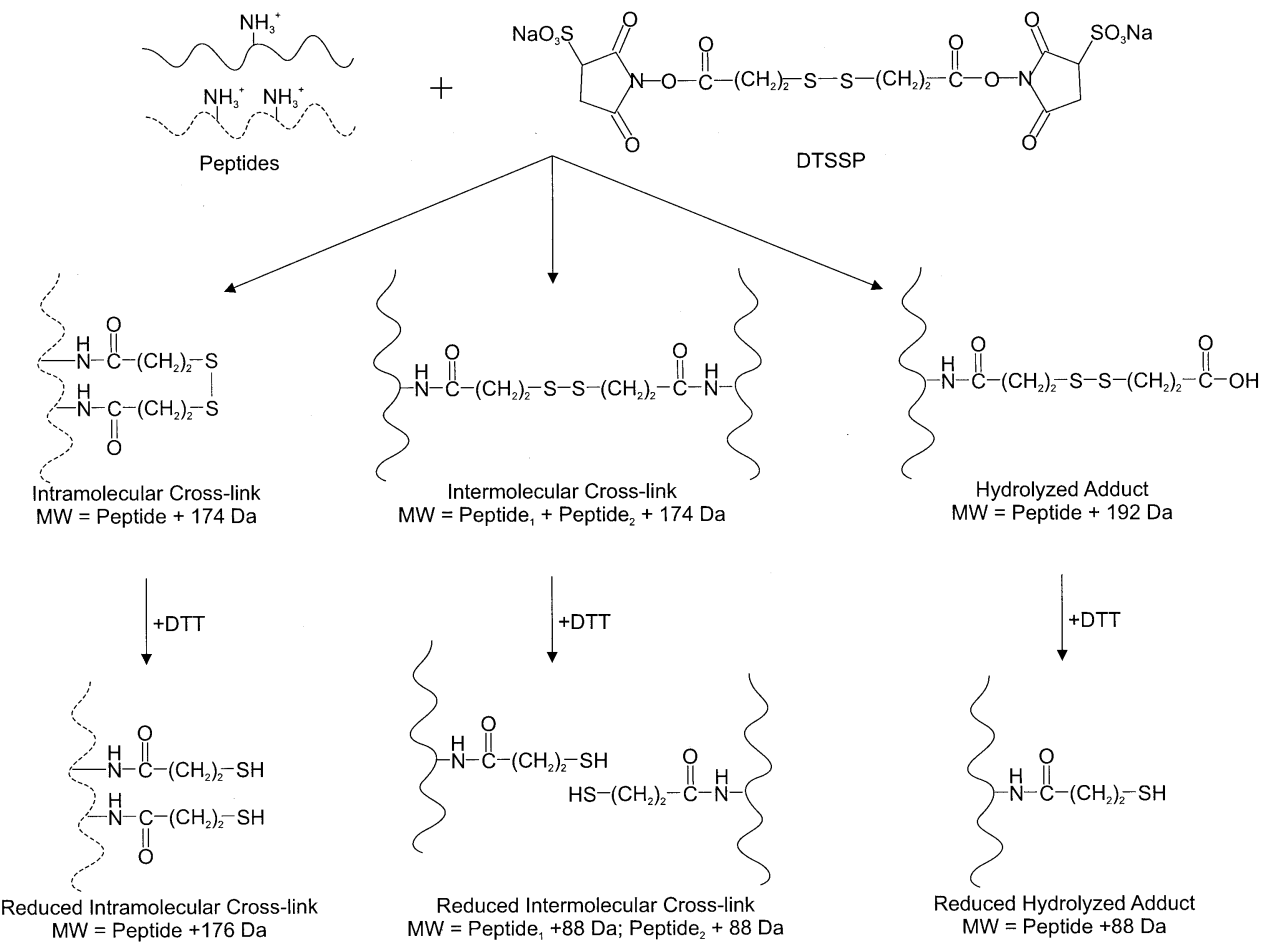

Figure 1. Reactions of DTSSP with peptides that have one or two reactive sites, indicated by solid and dashed lines, respectively. If DTSSP reacts with two residues within a peptide, it may form an intramolecular cross-link, thereby increasing the peptide molecular mass by $174 \mathrm{Da}$. Alternatively, DTSSP may react with residues in two different molecules to form an intermolecular cross-link. In this case, the molecular mass of the cross-linked peptides is given by the sum of the peptide masses plus $174 \mathrm{Da}$. Because DTSSP hydrolyzes rapidly in water, peptides may be detected with one or more adducts of hydrolyzed DTSSP. Each hydrolyzed adduct increases the molecular mass of the peptide by $192 \mathrm{Da}$. Treatment of any of these species with dithiothreitol (DTT) reduces the disulfide bond in DTSSP, resulting in mass increases of $88 \mathrm{Da}$ to the peptides.

are increased by $88 \mathrm{Da}$ for residues that reacted with DTSSP (Figure 1).

Our initial use of DTSSP to study the three-dimensional structure of $\alpha$-crystallin assemblies gave many products that could not be identified using the chemistry described in Figure 1. To better understand the chemistry of DTSSP and similar cross-linking reagents, we have studied the reaction of DTSSP with over 30 model peptides. Results of this study show that impurities in certain buffers can react with DTSSP, that impurities in the commercial DTSSP reagent react with the protein, and that DTSSP can react with residues other than Lys. Furthermore, this study shows that some of these products are particularly sensitive to in-source CID. Collectively, these results will aid in the interpretation of results of studies using commercial DTSSP to determine the three-dimensional structures of proteins.

\section{Experimental}

\section{Materials}

The cross-linking reagent 3,3'-dithiobis(sulfosuccinimidylpropionate) (DTSSP) was purchased from Pierce
Chemical Co. (Rockford, IL). Both potassium phosphate monobasic and sodium hydroxide were purchased from Mallinckrodt Chemical, Inc. (Paris, KY) and were of "Analytical Reagent" grade. Model peptides (Glufibrinopeptide B (gfp), angiotensin, $\alpha$-melanocyte stimulating hormone ( $\alpha$-MSH), G-5386 (GGYR), and leucine enkephalin (LeuEnk)) and proteins, carbonic anhydrase (CA) and bovine serum albumin (BSA), were purchased from Sigma Chemical Co. (St. Louis, $\mathrm{MO})$. Peptides and proteins from commercial sources were used without further purification. Dithiothreitol (DTT) and trypsin were also purchased from Sigma Chemical Co. Human lens $\alpha$-crystallins were isolated from an 11 year-old lens obtained from the Lions Eye Bank (Omaha, NE).

\section{Preparation and Separation of Water-Soluble $\alpha$-Crystallins}

Homogenization and size exclusion chromatography of the water-soluble human lens crystallins were conducted as previously described [14] except that DTT was excluded from the buffer. The $\alpha$-crystallins isolated from size exclusion chromatography were fractionated 
Table 1. Distribution of products formed by reaction of commercial DTSSP with model peptides whose only reactive site was the N-terminus

\begin{tabular}{|c|c|c|c|c|c|}
\hline \multirow[b]{2}{*}{ Peptide } & \multirow[b]{2}{*}{ Sequence } & \multirow[b]{2}{*}{ Unmodified } & \multicolumn{3}{|c|}{ Abundance $^{a}$} \\
\hline & & & +192 Da & +191 Da & +398 and $273 \mathrm{Da}$ \\
\hline CA9-15 & HDGPEHW & 14.2 & 42.4 & 7.0 & 36.4 \\
\hline CA сус-9-15 & cyc-HDGPEHW & 100.0 & - & - & - \\
\hline CA $18-26$ & DFPIANGER & 23.3 & 39.8 & 0.7 & 36.2 \\
\hline CA $18-26^{b}$ & DFPIADGER & 25.3 & 59.1 & 0.08 & 14.8 \\
\hline CA $20-26$ & PIANGER & 100.0 & - & - & - \\
\hline CA $20-26^{b}$ & PIADGER & 100.0 & - & - & - \\
\hline CA 58-65 & MVNNGHSF & 2.3 & 65.2 & 1.7 & 30.7 \\
\hline CA $58-65^{b}$ & MVNDGHSF & 1.9 & 64.9 & 1.2 & 32.0 \\
\hline$\alpha \mathrm{B} 12-17$ & RPFFPF & 2.8 & 81.0 & 3.3 & 12.8 \\
\hline gfp & EGVNDNEEGFFSAR & 40.3 & 41.5 & 4.4 & 13.8 \\
\hline cyc-gfp & EGVNDNEEGFFSAR & 100.0 & - & - & - \\
\hline
\end{tabular}

aPercent ion current was determined by dividing the ion current generated by each product of the DTSSP reaction by the sum of the ion current from all reaction products.

${ }^{\mathrm{b}}$ Residues 23 and 61 were found deamidated.

by reversed phase HPLC with an analytical column (Vydac C4, $4.6 \times 150 \mathrm{~mm}, 300 \AA$ ). . Proteins were eluted at a flow rate of $1 \mathrm{~mL} \mathrm{~min}{ }^{-1}$ using a binary gradient of water (Solvent A) and acetonitrile (Solvent B), both with $0.1 \%$ trifluoroacetic acid (TFA). The gradient increased Solvent B from 20 to $70 \%$ in 50 min. $\alpha$ A-Crystallin $(\alpha \mathrm{A})$ and $\alpha \mathrm{B}$-crystallin $(\alpha \mathrm{B})$ were detected at $280 \mathrm{~nm}$, collected and dried.

\section{Digestion of Proteins}

Digestions of BSA, CA, $\alpha \mathrm{B}$, and $\alpha \mathrm{A}$ were conducted at a 40:1 protein to trypsin ratio for $8 \mathrm{~h}$ at $37^{\circ} \mathrm{C}$ in $100 \mathrm{mM}$ ammonium bicarbonate, $\mathrm{pH}$ 8.2. Tryptic peptides were separated using a reversed phase HPLC analytical column (Vydac C18, $4.6 \times 150 \mathrm{~mm}, 300 \AA$ ) with a flow rate of $1 \mathrm{~mL} \min ^{-1}$ and a binary gradient of water (Solvent A) and acetonitrile (Solvent B), both with $0.1 \%$ TFA. The gradient increased Solvent B from $5-50 \%$ in $45 \mathrm{~min}$. The eluate was monitored at $214 \mathrm{~nm}$ and peptide concentrations were determined as previously described [15]. All peptides were reconstituted in water and stored at $-80{ }^{\circ} \mathrm{C}$ as $300 \mu \mathrm{M}$ stock solutions.

\section{Cross-Linking Reaction}

Peptide aliquots were diluted to $27 \mu \mathrm{M}$ in the reaction buffer (100 mM phosphate buffer adjusted to $\mathrm{pH} 6.7$ with $\mathrm{NaOH}$ ). A pH slightly lower than recommended in the DTSSP literature was chosen so that results would be applicable to future experiments with proteins that form disulfide bonds easily. Cross-linking reactions were initiated by addition of a freshly prepared solution of DTSSP to give a $5 \mathrm{M}$ excess of DTSSP. The solution was incubated at room temperature for 30 $\mathrm{min}$, then dried. To reduce disulfide bonds in products formed by reaction of CA 18-26 with DTSSP, half of the dried sample was resuspended in the same buffer containing $30 \mathrm{mM}$ DTT and incubated for $30 \mathrm{~min}$ at $37^{\circ} \mathrm{C}$. The same protocol was used to test the effect of ammonia on the distribution of products of the crosslinking reaction. For this experiment, the $\mathrm{pH}$ of the reaction buffer was adjusted to 6.7 with $\mathrm{NH}_{4} \mathrm{OH}$ rather than $\mathrm{NaOH}$.

\section{Product Analysis}

The products of the cross-linking reactions were reconstituted in water with $0.1 \%$ formic acid (FA) and then analyzed by online HPLC MS with a capillary column (LC Packings C18, $300 \mu \mathrm{m} \times 25 \mathrm{~cm}, 300 \AA$ A). Peptides were eluted at a flow rate of $5 \mu \mathrm{L} \mathrm{min}^{-1}$ using a binary gradient of water (Solvent $\mathrm{A}$ ) and acetonitrile (Solvent B), both with $0.1 \%$ FA. The gradient increased Solvent B from $5-50 \%$ in $45 \mathrm{~min}$. Molecular weights were determined using a quadrupole/time-of-flight electrospray ionization mass spectrometer (ESIMS) (Micromass Q-TOF+ or Q-TOF Ultima, Manchester, UK). The cone voltage was adjusted to give minimal fragmentation. The CID MS/MS analysis of each peptide was conducted using the collision energy that generated the most useful fragmentation. To determine the optimal energy for a peptide, a 200 fmol $\mu \mathrm{L}^{-1}$ solution ( $50 \%$ acetonitrile, $\left.0.1 \% \mathrm{FA}\right)$ was directly infused into the mass spectrometer while the collision energy was varied. For most peptides, optimal collision energy values were 25 and $15 \mathrm{eV}$ for $2+$ and $3+$ charge states, respectively.

\section{DTSSP Analysis}

An aliquot containing $1.3 \mu \mathrm{g}$ DTSSP (110 $\mu \mathrm{M}$ freshly prepared in $0.1 \% \mathrm{FA} ; \mathrm{pH} 2.1$ ) was loaded onto a capillary peptide trap (Michrom CapTrap $0.5 \times 2 \mathrm{~mm}$ ). The trapped reagent was washed for 5 min with water at a flow rate of $5 \mu \mathrm{L} \mathrm{min}{ }^{-1}$, and then eluted by stepping the concentration of acetonitrile to $50 \%(0.1 \%$ 

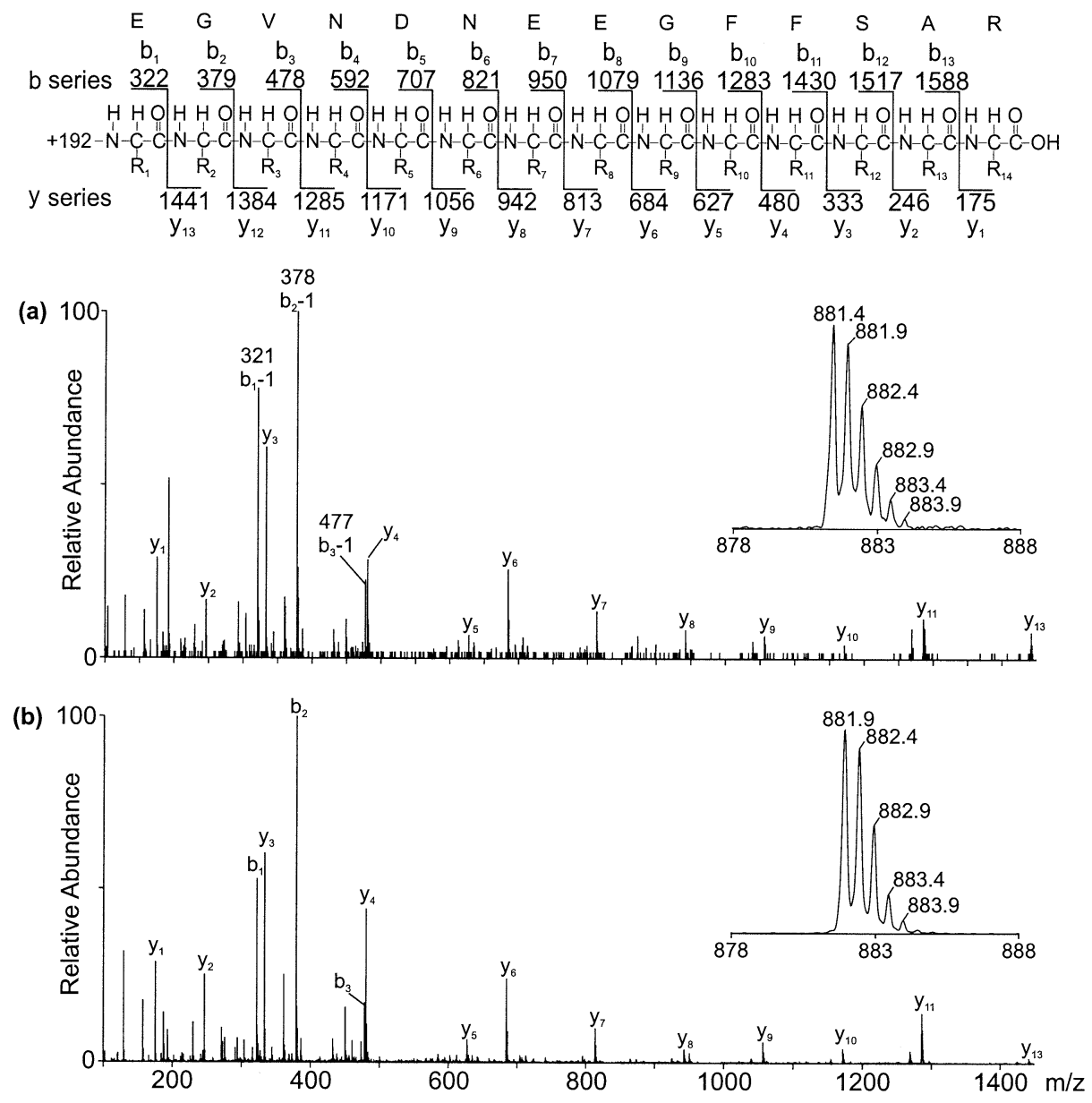

Figure 2. HPLC ESIMS analysis of two products formed by reaction of gfp (MW 1569.6) with commercial DTSSP. The gfp sequence is shown with masses for the $\mathrm{b}$ and $\mathrm{y}$ fragments that would result with a hydrolyzed adduct (+192 Da) at the N-terminus. (a) CID mass spectrum of $\mathrm{m} / \mathrm{z} 881.4^{2+}$, which is gfp with a mass increase of $191 \mathrm{Da}$. The mass spectrum of the parent ion is given in the inset. (b) CID mass spectrum of $m / z 881.9^{2+}$, which is gfp with a mass increase of $192 \mathrm{Da}$. The mass spectrum of the parent ion is given in the inset. The +191 Da adduct eluted just before the $+192 \mathrm{Da}$ adduct.

FA; pH 2.7). Molecular weights were determined using a quadrupole/time-of-flight hybrid mass spectrometer (Micromass Q-TOF+, Manchester, UK).

\section{Results and Discussion}

\section{Expected Products of the Reaction of DTSSP Were Detected}

All of the peptides studied yielded products showing reaction of DTSSP with primary amines, as depicted in Figure 1. For peptides that had only one reactive site, the only product detected was a hydrolyzed adduct (mass increase of $192 \mathrm{Da}$ ). For peptides with two reactive sites, the products had molecular weights corresponding to the peptide plus one hydrolyzed adduct (+192 Da), plus two hydrolyzed adducts (+384 Da), or with an intramolecular cross-link (+174 Da). Analysis of these modified peptides by CID MS/MS showed that DTSSP had reacted with the N-terminus and Lys residues, as expected. The peptide concentration was suf- ficiently low to minimize formation of intermolecular cross-linkages. None of the adducts contained the succinimidyl group originally at the ends of the DTSSP reagent. One succinimide is replaced as the cross-linker attaches to the peptide. The second succinimide may be replaced by reaction at another peptide residue or it may hydrolyze. Finding no adducts with a succinimidyl group shows that hydrolysis was complete within the 30 min reaction time. In addition to reaction of DTSSP with primary amines, as described above, several other products were detected for every peptide used in this study.

\section{Ammonium Salts Lead to Addition of $191 \mathrm{Da}$}

All the peptides that had products indicating an adduct of 192 Da (i.e., hydrolyzed DTSSP), also had a 191 Da adduct (Table 1). Based on ESIMS signals, the abundance of the $+191 \mathrm{Da}$ adduct was $1-17 \%$ of the +192 Da adduct for these experimental conditions. In 

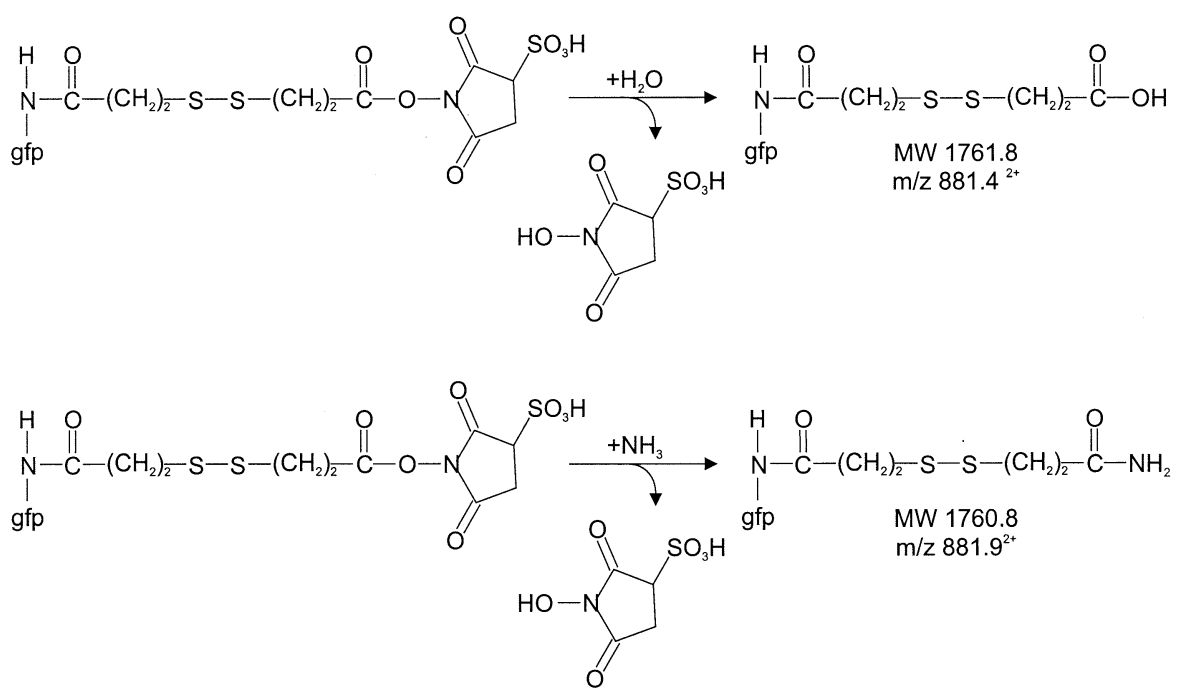

Scheme 1. Water and ammonia displacement reactions that lead to +192 and $+191 \mathrm{Da}$ adducts when cross linking studies using DTSSP are performed in the presence of ammonium ions.

the reversed phase HPLC separation of the products, the $+191 \mathrm{Da}$ adduct always eluted immediately before the $+192 \mathrm{Da}$ adduct, suggesting that the structures of the $+191 \mathrm{Da}$ and $+192 \mathrm{Da}$ modifications were similar. The CID MS/MS spectra of gfp (EGVNDNEEGFFSAR, MW 1569.7) with the +191 Da modification $\left(\mathrm{m} / \mathrm{z} 881.4^{2+}\right)$ and the $+192 \mathrm{Da}$ adduct $(\mathrm{m} / \mathrm{z}$ $881.9^{2+}$ ) are presented in Figure $2 a$ and $b$, respectively. Analysis of these spectra showed that fragments $y_{1}$ through $\mathrm{y}_{13}$ were unmodified, and that the masses of fragments $b_{1}$ through $b_{3}$ were increased by $191 \mathrm{Da}$ (Figure 2a) or $192 \mathrm{Da}$ (Figure 2b). These results showed that both modifications occurred at the N-terminus of gfp. No adducts were found for reaction of DTSSP with the control peptide, cyc-gfp.

Addition of an odd integer of mass (i.e., $191 \mathrm{Da}$ ) implied the addition of an odd number of nitrogens. Since the hydrolyzed adduct of DTSSP does not contain nitrogen (see Figure 1), other reactions that might lead to addition of nitrogen were considered. For example, the succinimide moiety of DTSSP could be replaced with ammonia rather than water. Reaction with ammonia would yield a product (i.e., an amide) with mass 1 Da less than the mass of the normal hydrolysis product (Scheme 1). The increased nucleophilicity of ammonia versus water makes this alternate mechanism likely, even in aqueous solutions where the ammonia concentration is very low. From the concentration of ammonium hydroxide in reagent grade sodium hydroxide and potassium phosphate used to prepare the solutions, it was calculated that the ammonia concentration may be as high as $18 \mathrm{nM}$. When this buffer was used for the reaction of DTSSP with angiotensin, the $191 \mathrm{Da}$ modification was only $2.9 \%$ of the combined ion currents for the 191 and $192 \mathrm{Da}$ adducts. In contrast, when the $\mathrm{pH}$ of the phosphate buffer was adjusted with $\mathrm{NH}_{4} \mathrm{OH}$, giving an ammonia concentration of $877 \mathrm{nM}, 50 \%$ of the combined ion currents for the 191 and 192 Da adducts was due to angiotensin with a mass increase of $191 \mathrm{Da}$ (data not shown). Since increasing ammonia concentration increased production of the $191 \mathrm{Da}$ adduct, this modification was attributed to the presence of low levels of ammonia in the reaction buffer. These results showed that even very low levels of ammonium impurities in the buffer salts can lead to substantial amounts of this unexpected product.

\section{Impurity in DTSSP Leads to Addition of $398 \mathrm{Da}$}

As shown in Table 1, all peptides that reacted with DTSSP to give the anticipated hydrolyzed adduct (+192 Da), as well as the $191 \mathrm{Da}$ adduct discussed above, also gave what appeared to be adducts of 273 and $398 \mathrm{Da}$. Based on their ESIMS signals, the combined abundance of these two unexpected adducts was $15-90 \%$ of the expected 192 Da adduct. Peptides with apparent adducts of 273 and 398 Da consistently co-eluted as the last peak of the chromatographic separation. For CA peptide 18-26 (DFPIANGER, MW 1017.5), HPLC MS analysis demonstrated that the elution time was $54.5 \mathrm{~min}$ for the product(s) giving ions corresponding to a $273 \mathrm{Da}$ adduct $\left(646.2^{2+}\right)$ and a $398 \mathrm{Da}$ adduct $\left(\mathrm{m} / \mathrm{z} 708.7^{2+}\right)$ (Figure $\left.3 \mathrm{a}\right)$. Thus, these unexpected products eluted $12 \mathrm{~min}$ after the elution of CA 18-26 with a hydrolyzed adduct (data not shown). Finding identical selected plots for ions at $\mathrm{m} / \mathrm{z} 646.2^{2+}$ and $708.7^{2+}$ indicated either co-elution of two different components or in-source CID of one component. Analysis of the CID MS/MS spectra of ions with $\mathrm{m} / \mathrm{z} 646.2^{2+}$ and $708.7^{2+}$ (Figure $3 \mathrm{~b}$ and $\mathrm{c}$ ) showed that the latter is the more likely explanation. Except for fragments at $m / z 1192.3^{1+}$ and $225.2^{1+}$ in the CID spectrum of $m / z 708.7^{2+}$ (note dashed lines in Figure 3), the CID spectra of parent ions for the 

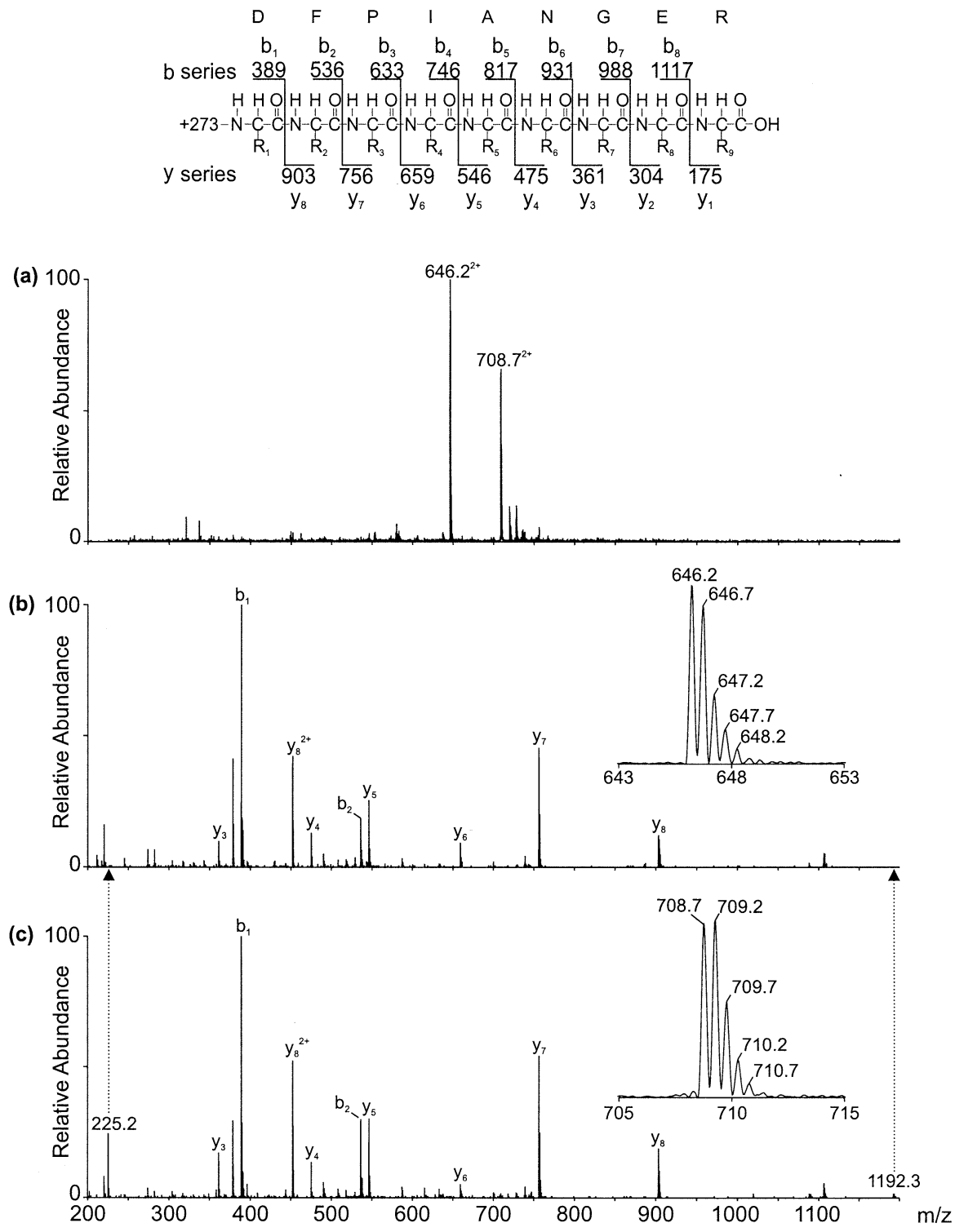

Figure 3. HPLC ESIMS analysis of unexpected products from the reaction of CA peptide 18-26 (MW 1017.5) with commercial DTSSP. The sequence of CA 18-26 is shown with masses for the $b$ and $y$ fragments that would result if a $273 \mathrm{Da}$ adduct were at the $\mathrm{N}$-terminus. (a) Mass spectrum from the chromatographic peak at $54.5 \mathrm{~min}$. Ions at $\mathrm{m} / \mathrm{z} 646.2^{+2}$ and $708.7^{+2}$ correspond to apparent adducts of 273 and $398 \mathrm{Da}$; (b) CID mass spectrum of $\mathrm{m} / \mathrm{z} 646.2^{2+}$ (inset); (c) CID mass spectrum of $\mathrm{m} / \mathrm{z} 708.7^{+2}$ (inset). Arrows from (c) to (b) emphasize absence of peaks at $m / z 225.2^{1+}$ and $1192.3^{1+}$ in the CID mass spectrum of $m / z 646.2^{2+}$.

apparent 273 and 398 Da adducts were judged to be identical. In both spectra, fragments $\mathrm{y}_{3}$ through $\mathrm{y}_{8}$ were unmodified, indicating that reaction with commercial DTSSP had modified the N-terminus of CA 18-26. Furthermore, the masses of the only $b$ fragments in both spectra $\left(b_{1}\right.$ and $\left.b_{2}\right)$ were increased by $273 \mathrm{Da}$. These results are consistent with formation of only one adduct, $+398 \mathrm{Da}\left(\mathrm{m} / z 708.7^{2+}\right)$, which fragmented easily in the ESI ion source to lose $125 \mathrm{Da}$, giving the apparent $273 \mathrm{Da}$ adduct $\left(\mathrm{m} / \mathrm{z} 646.2^{2+}\right)$. Absence of a significant peak at $\mathrm{m} / \mathrm{z} 646.2^{2+}$ in the CID MS/MS spectrum of the $398 \mathrm{Da}$ adduct (Figure 3c) suggests that this ion undergoes subsequent fragmentation to give the $b_{1}$ and $b_{2}$ ions with masses increased by $273 \mathrm{Da}$. The identities of the two ions unique to the CID spectrum of ions at $\mathrm{m} / \mathrm{z} 708.7^{2+}$ (i.e., $m / z 1192.3^{1+}$ and $225.2^{1+}$ ) are discussed below.

To help identify the unexpected $+398 \mathrm{Da}$ adduct, DTT was added to the sample to reduce any disulfide bonds. Analysis by HPLC MS of the reduced sample showed that the two chromatographic peaks corresponding to the +192 and $+398 \mathrm{Da}$ adducts (elution times 42 and $54.5 \mathrm{~min}$, respectively) were no longer present. These results indicated that the $+398 \mathrm{Da}$ ad- 

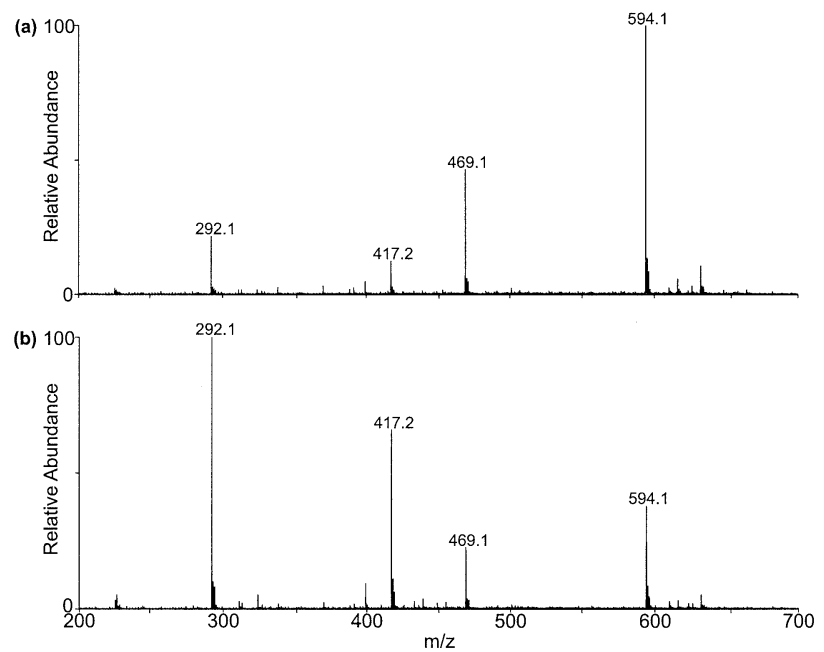

Figure 4. HPLC ESIMS analysis of commercial DTSSP. Mass spectra were acquired after incubating DTSSP in water for (a) 0 min and (b) $30 \mathrm{~min}$.

duct has a reducible disulfide bond, as expected for DTSSP. The chromatogram of the reduced material had only one peak, $\mathrm{m} / \mathrm{z} 553.7^{2+}$, corresponding to a $+88 \mathrm{Da}$ adduct. As indicated in Figure 1, this adduct was expected following reduction of any product formed by reaction of DTSSP. These results suggested that the 398 Da adduct may be due to an impurity in the commercial DTSSP which, like DTSSP, contains a disulfide bond.

To determine the purity of the DTSSP reagent, DTSSP was dissolved in water and analyzed by HPLC MS. Spectra of the unretained material had a peak at $\mathrm{m} / \mathrm{z}$ $630.9^{1+}$, which corresponded to the disodium salt of DTSSP with an additional sodium ion. Finding a peak for DTSSP only in the unretained material indicates that no DTSSP was retained under these chromatographic conditions. The mass spectrum of the major component of the retained material, which eluted when the mobile phase was stepped to $70 \%$ acetonitrile, is given in Figure 4 . The four major peaks present in this spectrum were attributed to products formed by the reaction of $\mathrm{N}, \mathrm{N}^{\prime}$-dicyclohexylcarbodiimide, (DCC), a catalyst used in the synthesis of DTSSP [16], with a partially hydrolyzed form of DTSSP. This reaction, as well as those responsible for the major peaks present in Figure 4, are described in Scheme 2. The initial product of this reaction has a molecular mass of 593.1, which gives the large peak at $\mathrm{m} / \mathrm{z} 594.1^{1+}$. Hydrolysis of this product with loss of the sulfosuccinimide (177 Da) gives the peak at $\mathrm{m} / \mathrm{z} 417.2^{1+}$. The peaks at $\mathrm{m} / \mathrm{z} 292.1^{1+}$ and $469.1^{1+}$ are due to loss of N-cyclohexylformamide (125 Da) through in-source CID of the parent ions at $\mathrm{m} / \mathrm{z}$ $417.2^{1+}$ and $594.1^{1+}$, respectively. This interpretation is supported by the mass spectrum of the same material taken after $30 \mathrm{~min}$ of hydrolysis (Figure $4 \mathrm{~b}$ ). Further hydrolysis during this time led to a substantial increase in the peak at $\mathrm{m} / \mathrm{z} 417.2^{1+}$ relative to the peak at $\mathrm{m} / \mathrm{z}$ 594.1. However, the ratios of the peaks due to in-source

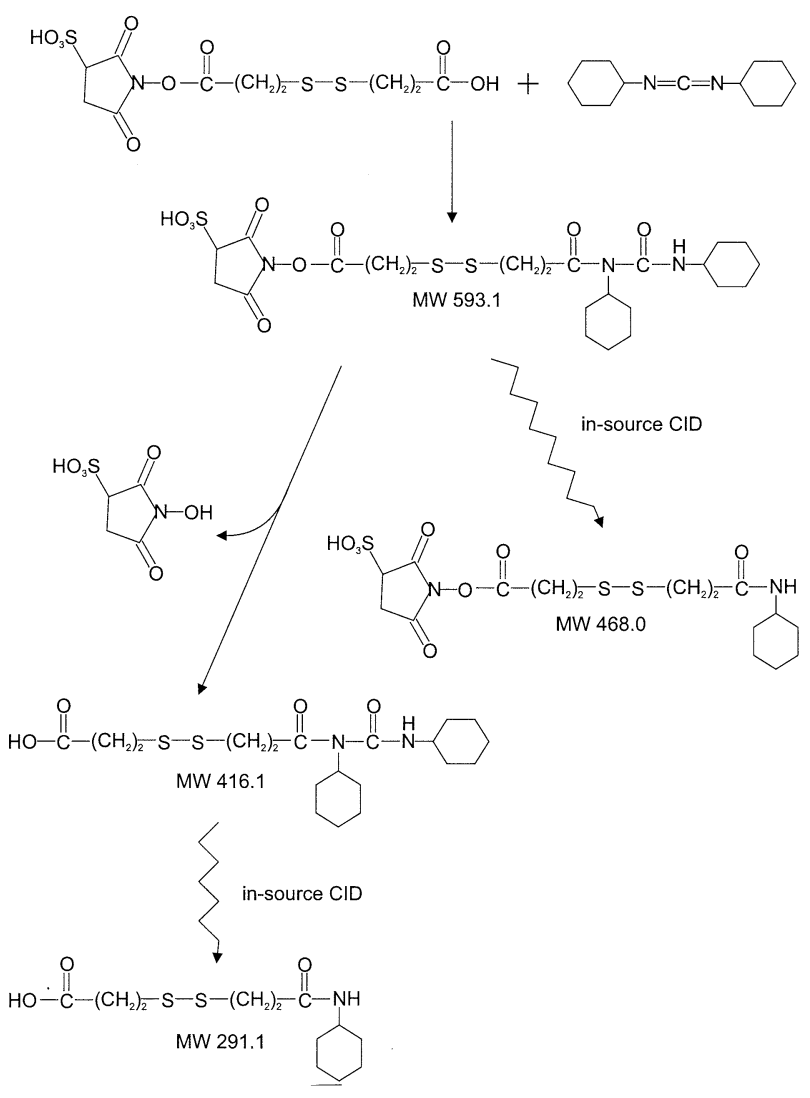

Scheme 2. Reactions occurring in commercial DTSSP that explain peaks found in the mass spectrum (Figure 4) of an impurity that leads to the +398 peptide adduct (Figure 3 ).

loss of N-cyclohexyformamide $\left(\mathrm{m} / \mathrm{z} \quad 292.1^{1+}\right.$ and $\left.469.1^{1+}\right)$ to their parent ions $\left(\mathrm{m} / \mathrm{z} 417.2^{1+}\right.$ and $594.1^{1+}$, respectively) changed little with hydrolysis time. The interpretation was confirmed by experiments using different sampling cone voltages in the electrospray interface which showed that the amount of fragmentation increased with increasing cone voltage (unpublished results).

The reactions illustrated in Scheme 2 offer an explanation for the unexpected products formed by reaction of commercial DTSSP with CA peptide 18-26. Addition of the impurity DCC-DTSSP to CA 18-26 would generate the $398 \mathrm{Da}$ adduct with molecular mass of 1415.4 $\left(\mathrm{m} / \mathrm{z} 708.7^{2+}\right.$, Figure $\left.3 a\right)$. In-source CID of this adduct leads to loss of N-cyclohexyl formamide (125 Da), to give the apparent $273 \mathrm{Da}$ adduct with molecular mass $1290.4\left(\mathrm{~m} / \mathrm{z} 646.2^{2+}\right.$, Figure 3a). In the CID MS/MS spectrum of $\mathrm{m} / \mathrm{z} 708.7^{2+}$ (Figure 3c), the ion at $\mathrm{m} / \mathrm{z}$ $1192.3^{1+}$ is attributed to loss of $\mathrm{N}, \mathrm{N}^{\prime}$-dicyclohexylurea $(224 \mathrm{Da})$ from the molecular ion for DCC-DTSSP-CA $18-26$, while $m / z 225.2^{1+}$ is the $\mathrm{MH}^{+}$of $\mathrm{N}, \mathrm{N}^{\prime}$-dicyclohexylurea (224 Da). Because $m / z 646.2^{2+}$ is attributable to the in-source CID product with only one remaining $\mathrm{N}$-cyclohexyl formamide group, it could not undergo loss of $\mathrm{N}, \mathrm{N}^{\prime}$-dicyclohexylurea to form the ions at $\mathrm{m} / \mathrm{z}$ $1192.2^{1+}$ and $225.2^{1+}$. 


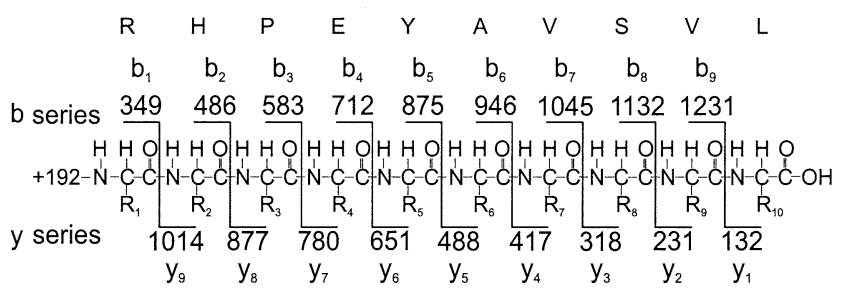

(a)

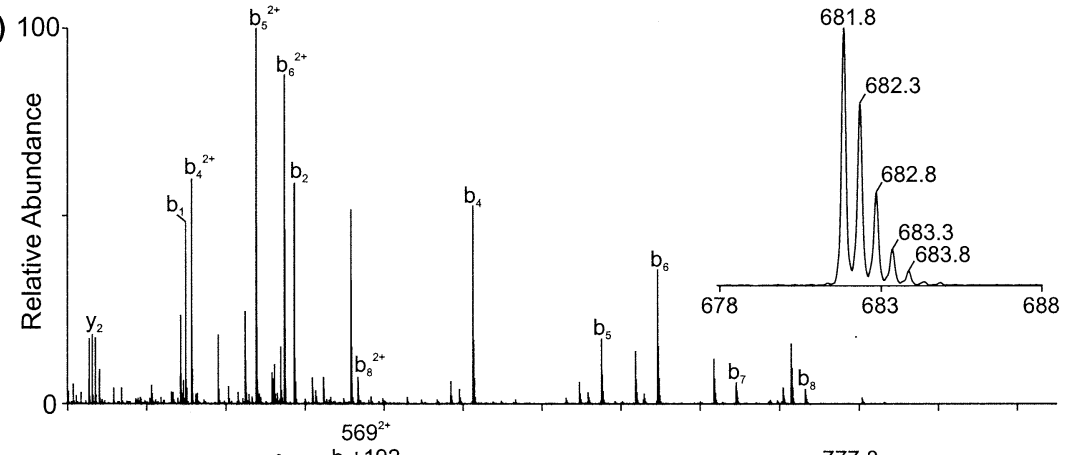

(b)

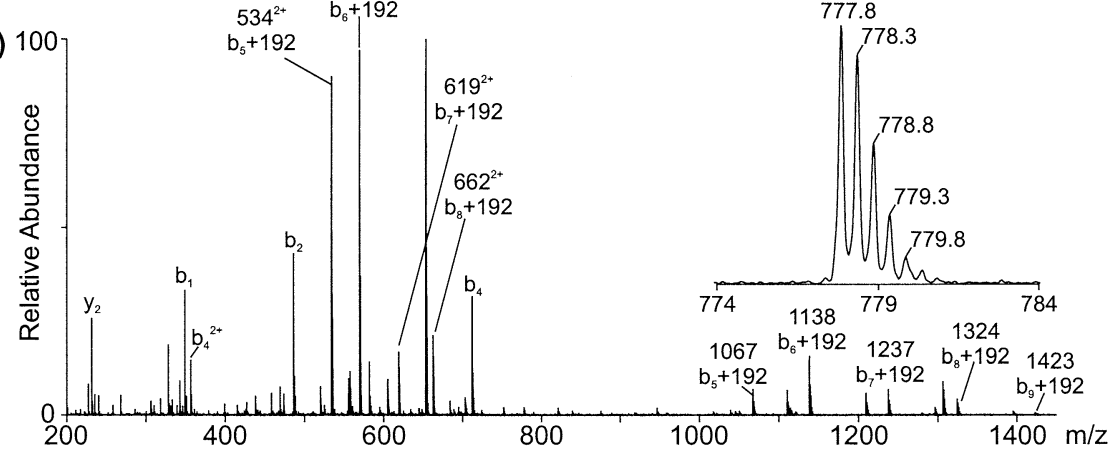

Figure 5. HPLC ESIMS analysis of products from the reaction of BSA peptide 336-345 (MW 1169.6) with DTSSP. The sequence of BSA 336-345 is shown with masses for the $b$ and $y$ fragments that would result with a hydrolyzed adduct at the N-terminus. (a) CID mass spectrum of $m / z 681.8^{2+}$ (BSA 336-345 with one hydrolyzed DTSSP adduct). The mass spectrum of the parent ion is given in the inset. (b) CID mass spectrum of $m / z 777.8^{2+}$ (BSA 336-345 with two hydrolyzed DTSSP adducts). The mass spectrum of the parent ion is given in the inset.

These results showed that whenever DCC is used as a catalyst in the synthesis of DTSSP or related crosslinking agents, the reagent may include impurities that react with the protein. Furthermore, the facile in-source fragmentation of this adduct will complicate interpretation of mass spectra.

\section{DTSSP Reactivity is not Limited to Primary Amines}

Literature accompanying the commercial DTSSP cross-linking reagent (Pierce Chemical Co.) suggests that its reactivity is limited to primary amines. A study of the reactivity of isolated amino acids with N-hydroxysulfosuccinimide esters similar to DTSSP detected minor products formed by reaction with tyrosine and cysteine. No stable products were found for reaction with tryptophan, histidine, serine, or threonine [17]. Although reaction with polypeptides is expected to be more complicated, reaction of
DTSSP with functionalities other than primary amines has not been reported. Thus, reaction only with Lys residues and the N-terminus was expected. However, reaction of DTSSP with several peptides whose sequences did not include Lys showed that reaction can occur readily with other residues, particularly tyrosine. For example, the model peptide BSA 336-345 (RHPEYAVSVL, MW 1169.6) was found with both an intramolecular cross-link and two hydrolyzed adducts after reaction with DTSSP. To determine the second point of attachment, the CID MS/MS spectra of this peptide with one hydrolyzed adduct $\left(\mathrm{m} / \mathrm{z} 681.8^{2+}\right)$ and two hydrolyzed adducts $\left(\mathrm{m} / z 777.8^{2+}\right)$ were compared (Figure 5). Fragments $b_{1}, b_{2}$, and $b_{4}$ through $b_{8}$ in the spectrum of the peptide with one hydrolyzed adduct had mass increases consistent with an adduct of $192 \mathrm{Da}$ at the N-terminus (Figure 5a). Similar results were found for fragments $b_{1}, b_{2}$, and $b_{4}$ for the peptide with two hydrolyzed adducts (Figure $5 b$ ), again demonstrating 

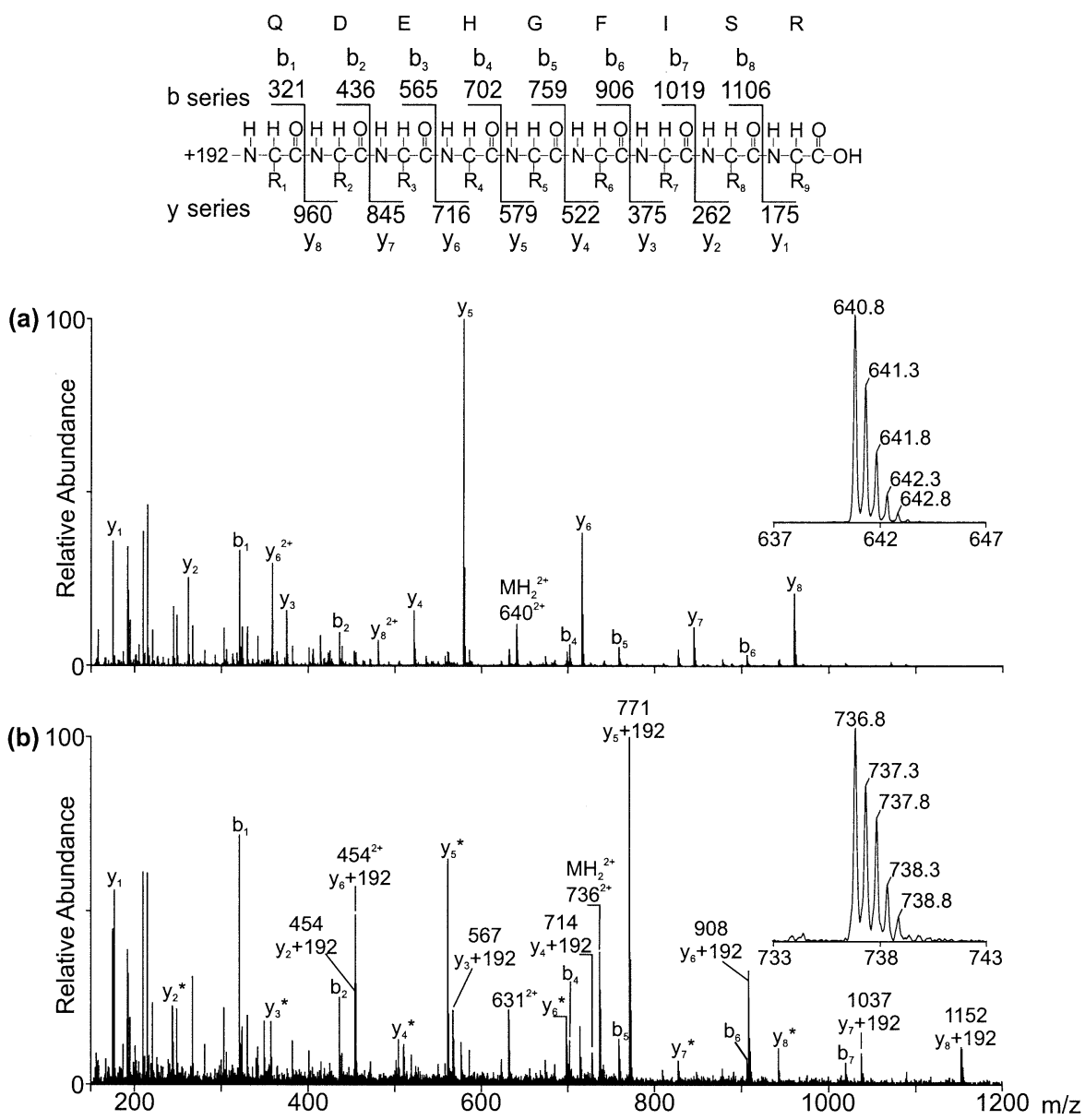

\begin{abstract}
Figure 6. HPLC ESIMS analysis of products from the reaction of $\alpha \mathrm{B}$ peptide 108-116 (MW 1087.5) with DTSSP. The sequence of $\alpha \mathrm{B} 108-116$ is shown with masses for the $\mathrm{b}$ and $\mathrm{y}$ fragments that would result with a hydrolyzed adduct at the N-terminus. (a) CID mass spectrum of $m / z 640.8^{2+}(\alpha \mathrm{B} 108-116$ with one hydrolyzed DTSSP adduct). The mass spectrum of the parent ion is given in the inset. (b) CID mass spectrum of $m / z 736.8^{2+}$ ( $\alpha \mathrm{B} 108-116$ with two hydrolyzed DTSSP adducts). The mass spectrum of the parent ion is given in the inset. Peaks with masses 18 Da less than masses calculated for $y$ fragments of the unmodified peptide are indicated by asterisks.
\end{abstract}

reaction of DTSSP with the N-terminus of the peptide. However, the masses of fragments $b_{5}$ through $b_{8}$ were increased by an additional $192 \mathrm{Da}$, and the masses of $\mathrm{y}_{2}$ through $\mathrm{y}_{8}$ were also increased by 192 Da. These results demonstrated that DTSSP had also reacted with Tyr 5 .

Another model peptide that contained neither lysine nor tyrosine, $\alpha \mathrm{B}$ 108-116 (QDEHGFISR, MW 1087.6), also had two hydrolyzed adducts. The second point of attachment was determined by comparing the CID MS/MS spectra of $\alpha \mathrm{B} 108-116$ with one and two hydrolyzed adducts $\left(\mathrm{m} / \mathrm{z} 640.8^{2+}\right.$ and $\left.\mathrm{m} / \mathrm{z} 736.8^{2+}\right)$, respectively; Figure 6. The masses of fragments $\mathrm{y}_{1}$ through $\mathrm{y}_{8}$, as well as the masses of fragments $b_{1}, b_{2}$, and $b_{4}$ through $b_{6}$, found in the CID MS/MS spectrum of this peptide with one hydrolyzed adduct demonstrated that the adduct was located at the N-terminus. The CID MS/MS spectrum of this peptide with two hydrolyzed adducts was similar (Figure $6 b$ ). Fragments $b_{1}, b_{2}$, and $b_{4}$ through $b_{6}$ had mass increases of $192 \mathrm{Da}$, demonstrating that one hydrolyzed adduct was located at the $\mathrm{N}$-terminus, and that the second hydrolyzed adduct was not among the first six residues. Unlike the peptide with only one hydrolyzed adduct $\left(m / z 640.8^{2+}\right)$, fragments $\mathrm{y}_{2}$ through $\mathrm{y}_{8}$ were also increased by $192 \mathrm{Da}$. The only unmodified y fragment in the CID MS/MS spectrum of this peptide with two adducts was $\mathrm{y}_{1}$. These results demonstrated that the second hydrolyzed adduct was at Ser 8 .

The general propensity of DTSSP to react with tyrosine and serine residues was investigated using 17 model peptides. These results, which are summarized in Table 2 , show that $85 \%$ of the tyrosine residues and $40 \%$ of the serine residues reacted with DTSSP under the present experimental conditions. The only tyrosine containing peptide that did not react with DTSSP was $\alpha$ A peptide 35-57. Perhaps, the length of $\alpha$ A 35-57 and the presence of two prolines provided some secondary structure that limited the reactivity of the tyrosines. The sequences of the serine containing peptides were also examined for correlations between sequence and reac- 
Table 2. Unexpected reactivity of DTSSP with tyrosine and serine residues ${ }^{\mathrm{a}}$

\begin{tabular}{|c|c|c|c|c|c|}
\hline \multirow[b]{2}{*}{ Peptide } & \multirow[b]{2}{*}{ Sequence } & \multicolumn{4}{|c|}{ Point of Modification } \\
\hline & & N-terminus & Lysine & Tyrosine & Serine \\
\hline CA 27-35 & QSPVDIDTK & Yes & Yes & - & No \\
\hline CA сус-27-35 & сус-QSPVDIDTK & - & Yes & - & No \\
\hline CA 58-65 & MVNNGHSF & Yes & - & - & No \\
\hline CA $58-65^{a}$ & MVNDGHSF & Yes & - & - & No \\
\hline CA 95-106 & HWGSSDDQGSEH & Yes & - & - & Yes \\
\hline CA 158-166 & VLDALDSIK & Yes & Yes & - & No \\
\hline$\alpha \mathrm{B} 83-90$ & HFSPEELK & Yes & Yes & - & Yes \\
\hline$\alpha \mathrm{B}$ 108-116 & QDEHGFISR & Yes & - & - & Yes \\
\hline$\alpha \mathrm{A} 35-57$ & $\begin{array}{l}\text { DLLPFLSSTISPYYRQSLF } \\
\text { RTVL }\end{array}$ & Yes & - & No & No \\
\hline BSA 106-173 & YNGVFQECCQAQNK & Yes & Yes & Yes & - \\
\hline BSA 336-345 & RHPEYAVSVL & Yes & - & Yes & Yes \\
\hline Angiotensin & DRVYIHPFHL & Yes & - & Yes & - \\
\hline$\alpha-\mathrm{MSH}$ & ac-SYSMEHFRWGKPV & no & Yes & Yes & Yes \\
\hline G-5386 & GGYR & Yes & - & Yes & - \\
\hline LeuEnk & YGGFL & Yes & - & Yes & - \\
\hline gfp & EGVNDNEEGFFSAR & Yes & - & - & No \\
\hline cyc-gfp & cyc-EGVNDNEEGFFSAR & - & - & - & No \\
\hline
\end{tabular}

${ }^{\text {a Residue }} 61$ was found deamidated.

tivity of serine, but no trends were evident. Since reaction of DTSSP with tyrosine and serine residues has been demonstrated, these products must be considered when using DTSSP for the structural analysis of proteins.

\section{CID Fragmentation of DTSSP Adducts to Ser}

The stability of bonds joining the DTSSP adduct to lysine, tyrosine and serine sidechains was studied by CID MS/MS. Although there was no evidence for loss of the DTSSP adduct from lysine or tyrosine sidechains, strong peaks corresponding to this loss from serine were present in the CID spectra of serine-DTSSP adducts. For example, peaks marked by an asterisk in the CID spectrum of $\alpha \mathrm{B} 108-116$ (Figure 6b) have masses that are 18 Da less than the fragment masses expected for this peptide with serine unmodified. Prominent peaks corresponding to $\mathrm{y}_{2}$ through $\mathrm{y}_{8}$ less $18 \mathrm{Da}$ are present in this spectrum. Furthermore, the peak at $m / z 631.8^{2+}$, which was formed by loss of 210 Da from the molecular ion, provides additional evidence for loss of the DTSSP adduct from serine. Peaks corresponding to this loss were not present in the CID mass spectra of peptides with DTSSP adducts at residues other than serine. Fragmentation of the DTSSP-serine linkage is illustrated in Scheme 3a.

Evidence for cleavage of the DTSSP-serine bond was found in the CID mass spectra of several other peptides. For example, the CID mass spectrum of $\alpha$-MSH (acSYSMEHFRWGKPV, MW 1664.7) with two hydrolyzed adducts showed a loss of $210 \mathrm{Da}$ from the parent ion, as well as several $b$ fragments with mass deficits of $18 \mathrm{Da}$ (data not shown). There was also evidence of fragmentation of the DTSSP-serine linkage when it formed an intramolecular cross-link between the N-terminus and Ser 8 of BSA peptide 336-345 (RHPEYAVSVL, MW 1170.6). In addition to the normal fragments used to determine the location of this cross-link, there was a series of intense ions corresponding to $b_{1}, b_{2}$, and $b_{4}$
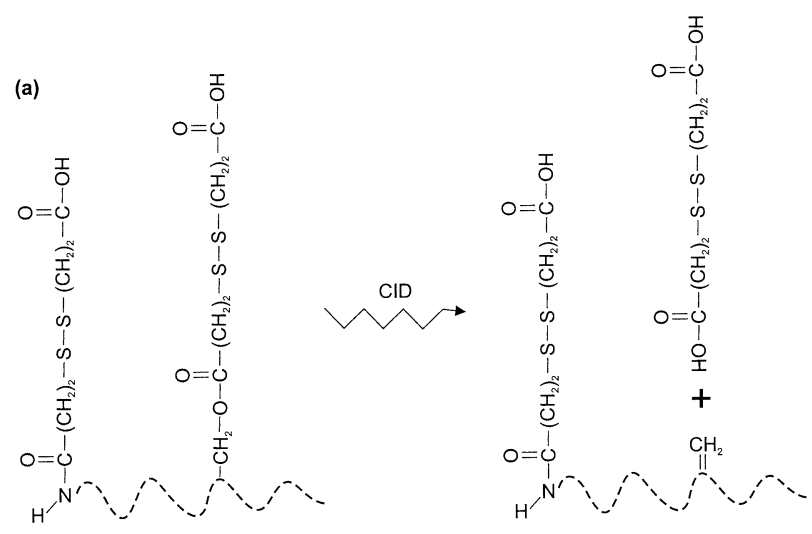

$\mathrm{m} / \mathrm{z} 736.8^{2+}$

$\mathrm{m} / \mathrm{z} 631.8^{2+}$

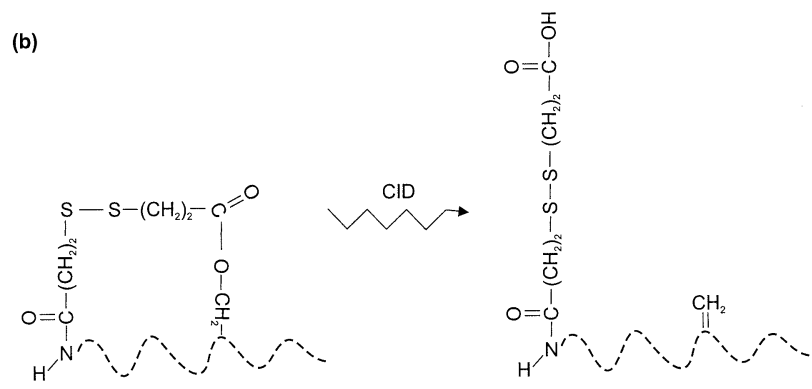

Scheme 3. Fragmentation of DTSSP-Ser adducts illustrated in Figure 6. 

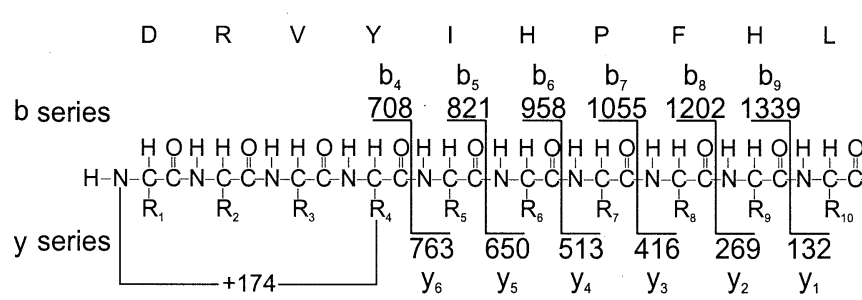

$\underline{708} \underline{821} \underline{958} \underline{1055} \underline{1202} \underline{1339}$

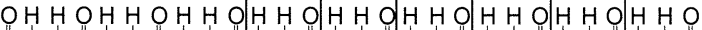

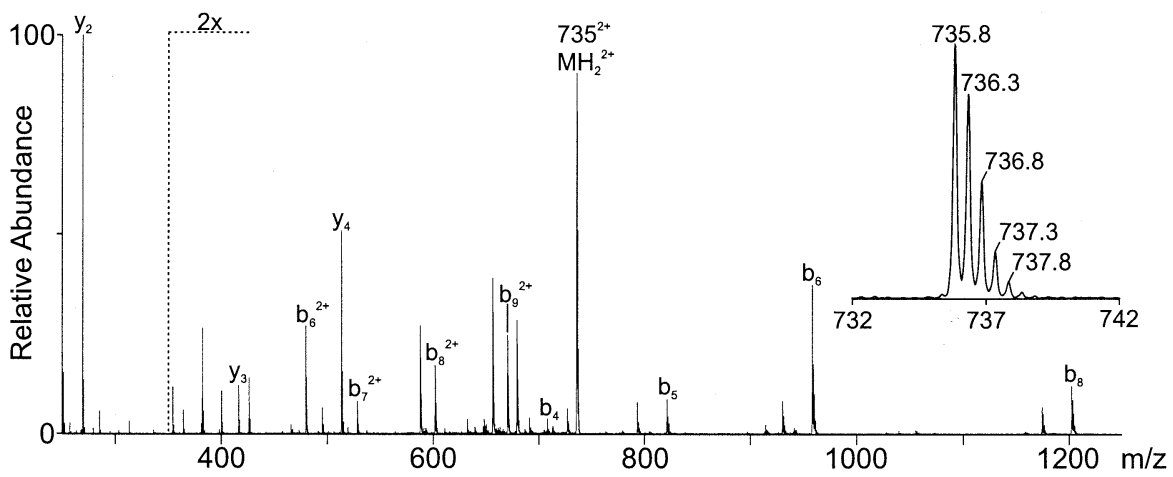

Figure 7. HPLC ESIMS/MS analysis of angiotensin with an intramolecular cross-link, which increased the molecular weight of the peptide to 1469.6 (i.e., a mass increase of $174 \mathrm{Da}$,). The sequence of angiotensin is shown with masses for the $b$ and $y$ fragments of the cross-linked peptide. The mass spectrum of the parent ion is given in the inset.

through $b_{6}$ with mass increases of $192 \mathrm{Da}$ (data not shown). These fragments would result if the bond between the DTSSP modification and Ser 8 were cleaved while the DTSSP modification at the N-terminus remained intact (Scheme $\mathbf{3 b}$ ).

\section{CID Fragmentation of Peptides with Intramolecular DTSSP Cross-Linkages}

Identification of peptides with intramolecular crosslinkages formed by DTSSP is an important step in using this reagent to study the three-dimensional structures of proteins. Preliminary identification is most easily made from the molecular weights of peptides and the now known reactivity of DTSSP with lysine, tyrosine and serine residues. The CID spectra of these peptides may be used to confirm their identity and to locate more accurately the DTSSP cross-linkages. However, presence of intramolecular DTSSP cross-linkages can substantially alter their collision induced dissociation, thereby complicating interpretation of their CID mass spectra. Angiotensin (DRVYIHPFHL) with an intramolecular cross-link is an example a peptide where only a small region is cyclized by the DTSSP cross-linkage. The CID mass spectrum of this modified peptide, which is presented in Figure 7, has major peaks for $b_{4}$ through $b_{9}$, as well as for $y_{3}$ and $y_{4}$. These peaks are sufficient to confirm the identity of this peptide and to establish the DTSSP cross-linkage between the N-terminus and Tyr 4. No peaks in the CID spectrum could be attributed to fragmentation of the cyclized region. Thus, although the CID mass spectrum of this peptide differs substan- tially from that of the unmodified peptide (not shown), it is still easily interpreted.

In contrast to the relatively simple case of angiotension, CID fragmentation of CA 158-166 where the entire peptide is cyclized by DTSSP is very complicated because informative fragment ions are formed only when two bonds are broken. That is, one bond must be broken to "linearize" the ring followed by breaking of a second bond to produce a fragment with a distinctive mass. Similar complex spectra have been reported for CID of cyclic peptides and a nomenclature for describing their fragments has been established [18, 19]. Cleavage of the "linearized" peptide may give " $b$ " fragments, which are designated by the subscript " $\mathrm{XXY}$ ". The N- and Cterminal residues of the linearized peptide correspond to " $\mathrm{X}$ " and " $\mathrm{Y}$ ", respectively, while " $\mathrm{n}$ " denotes the number of residues retained in the fragment. For example, cleavage of the amide bond between Ile 8 and Lys 9 of CA 158-166 with an intramolecular cross-link between the $\mathrm{N}$-terminus and Lys 9 generates a linear structure with lysine at one end and isoleucine at the other end. Cleavage after Val 1, Leu 2, and Asp 3 generates the fragments $b_{2 \mathrm{KI}}, b_{3 \mathrm{KI}}$, and $b_{4 \mathrm{KI}}$, respectively. Because any of several different bonds may be broken to linearize the cross-linked peptide, the CID mass spectra may be very complex. However, analysis of the CID mass spectrum of cross-linked CA 158-166 (Figure 8) shows that most of the peaks can be identified. For instance, all possible $b$ fragments from the linear structure with lysine and isoleucine at the ends $\left(b_{2 \mathrm{KI}}\right.$ through $\left.b_{8 \mathrm{KI}}\right)$ were detected. Furthermore, the smallest fragment possible that involves the intramolec- 


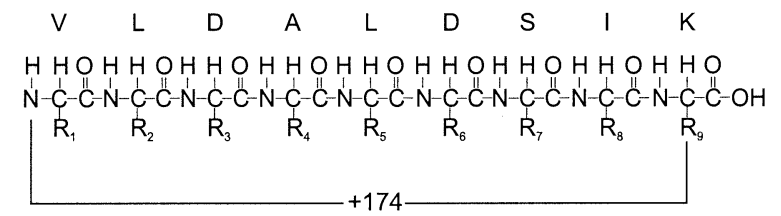

\begin{tabular}{|c|c|c|c|c|c|c|c|c|c|c|c|c|c|c|c|c|}
\hline & & $b_{n K l}$ & & $b_{\text {nIs }}$ & & $b_{n S D}$ & & $b_{n D L}$ & & $b_{n L A}$ & & $b_{n A D}$ & & $b_{n D L}$ & & $b_{n L V}$ \\
\hline 9 & Ile & & Ser & & Asp & & Leu & & $\mathrm{Ala}$ & & Asp & & Leu & & Val & \\
\hline 8 & Ser & 1034 & Asp & - & Leu & - & $\mathrm{Ala}$ & 1034 & Asp & - & Leu & - & Val & 1034 & Lys & $\mathrm{n} / \mathrm{a}$ \\
\hline 7 & Asp & 947 & Leu & - & Ala & 919 & Asp & - & Leu & - & Val & 919 & Lys & $\mathrm{n} / \mathrm{a}$ & Ile & - \\
\hline 6 & Leu & 832 & Ala & 832 & Asp & 848 & Leu & 848 & Val & 848 & Lys & $\mathrm{n} / \mathrm{a}$ & Ile & - & Ser & - \\
\hline 5 & Ala & 719 & Asp & 761 & Leu & - & Val & 735 & Lys & $\mathrm{n} / \mathrm{a}$ & Ile & 500 & Ser & 502 & Asp & 528 \\
\hline 4 & Asp & 648 & Leu & - & Val & - & Lys & $\mathrm{n} / \mathrm{a}$ & Ile & - & Ser & 387 & Asp & - & Leu & 413 \\
\hline 3 & Leu & 533 & Val & 533 & Lys & $\mathrm{n} / \mathrm{a}$ & Ile & 316 & Ser & 316 & Asp & 300 & Leu & 300 & Ala & 300 \\
\hline 2 & Val & 420 & Lys & $\mathrm{n} / \mathrm{a}$ & Ile & 201 & Ser & 203 & Asp & 229 & Leu & 185 & Ala & 187 & Asp & 229 \\
\hline 1 & Lys & $\mathrm{n} / \mathrm{a}$ & Ile & - & Ser & - & Asp & - & Leu & - & Ala & - & Asp & - & Leu & - \\
\hline
\end{tabular}

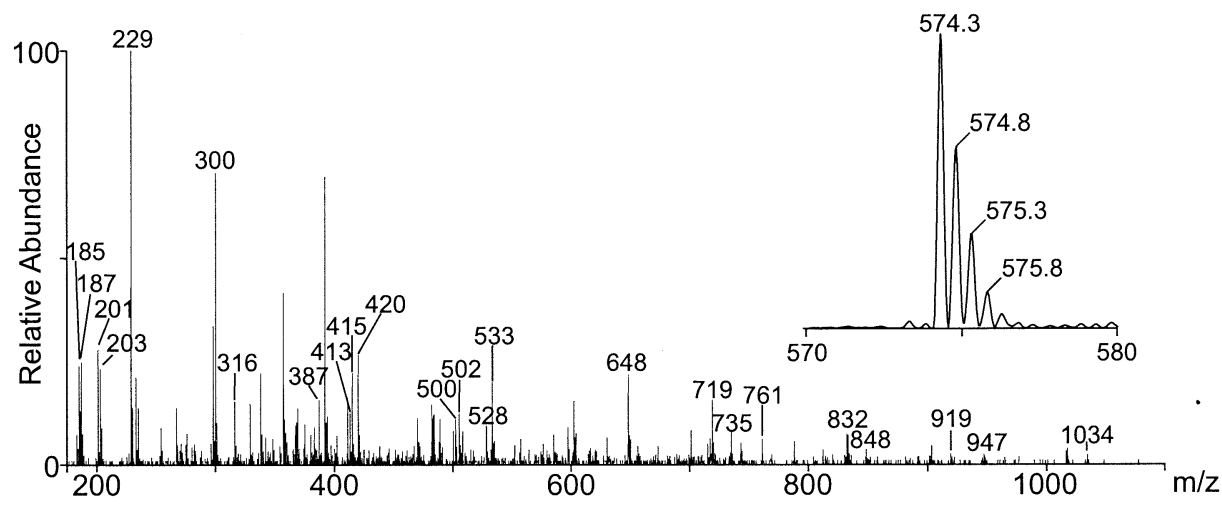

Figure 8. HPLC ESIMS/MS analysis of CA peptide 158-166 (MW 972.5) with an intramolecular cross-link between the $\mathrm{N}$-terminal Val and the C-terminal Lys $\left(\mathrm{m} / z 574.3^{2+}\right)$. The mass spectrum of the parent ion is given in the inset to the CID mass spectrum. The $m / z$ of the $\boldsymbol{b}$ fragments formed following ring opening at various points along the peptide backbone are given in the table. A dash replaces the $\mathrm{m} / \mathrm{z}$ of fragments not detected. The $\mathrm{m} / \mathrm{z}$ of fragments whose generation would require cross-linker cleavage are replaced by $n$ /a because no cleavage of DTSSP bound to primary amines has been detected.

ular cross-link between the N-terminus and Lys $9, \mathrm{~b}_{2 \mathrm{KI}}$ $\left(\mathrm{m} / \mathrm{z} 420^{1+}\right)$ was detected. Presence of this ion and the absence of fragments corresponding to a cross-link between any other residues confirmed that the intramolecular cross-link of CA 158-166 was between the Nterminus and Lys 9.

\section{Modification Weakens Amide Bond Strength}

Fragments formed by in-source CID can complicate identification of cross-linked peptides in protein digests. Our initial analysis of $\alpha$-MSH (ac-SYSMEHFRWGKPV, MW 1664.7) showed in-source CID between Lys 11 and Pro 12, consistent with previous studies reporting that amide bonds preceding prolines are particularly susceptible to cleavage [20]. To avoid this fragmentation, the cone voltage in the ESI source was decreased so that the only ions in the mass spectrum of the unmodified $\alpha-\mathrm{MSH}$ corresponded to the $2+$ and $3+$ states of the parent (data not shown). Similarly, the only ions in the mass spectrum of $\alpha$-MSH with a hydrolyzed adduct at Tyr 2 corresponded to the $2+$ and $3+$ states of the parent ions (data not shown). Despite these mild conditions, the mass spectrum of $\alpha$-MSH modified at Lys 11 showed evidence of fragmentation of the amide linkage joining Lys 11 and Pro 12 (Figure 9). In addition to peaks for the $2+$ and $3+$ charge states of the $\alpha$-MSH molecular ion with a hydrolyzed adduct at Lys $11(\mathrm{~m} / \mathrm{z}$ $929.5^{2+}$ and $620.0^{3+}$, respectively), there is a peak corresponding to the $b_{11}$ fragment $\left(\mathrm{m} / z 822.4^{2+}\right)$. Other major peaks in this spectrum are due to co-elution of $\alpha$-MSH with an intramolecular cross-link between Tyr 2 and Lys 11 . In addition to $2+$ and $3+$ charge states for the molecular ion $\left(\mathrm{m} / \mathrm{z} 920.5^{2+}\right.$ and $613.9^{3+}$, respectively), there is a peak corresponding to the $b_{11}$ fragment $\left(m / z 813.4^{2+}\right)$. These $b_{11}$ fragments indicated that the binding of DTSSP at Lys 11, whether as a hydrolyzed adduct or as part of a cross-link, further strained an amide bond already weakened by proline. These results show that addition of DTSSP can 


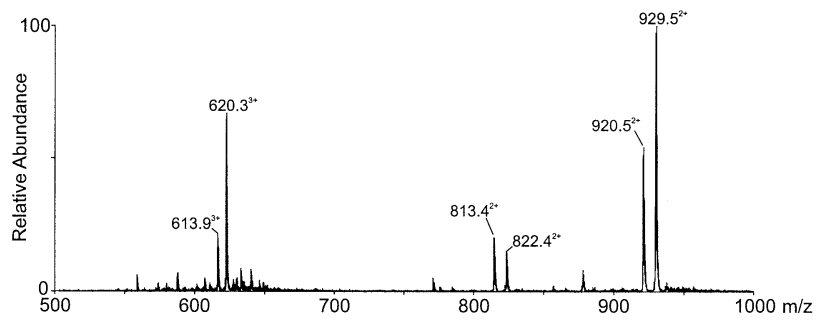

Figure 9. HPLC ESIMS analysis of two products formed by addition of DTSSP to Lys 11 of $\alpha$-MSH (ac-SYSMEHFRWGPKV, MW 1664.7). Ions with $\mathrm{m} / \mathrm{z} 620.0^{3+}$ and $929.5^{2+}$ correspond to molecular ions of this peptide with a hydrolyzed adduct at Lys 11 . Ions with $\mathrm{m} / \mathrm{z} 613.9^{3+}$ and $920.5^{2+}$ correspond to molecular ions of this peptide with an intramolecular cross-link between Tyr 2 and Lys 11. Ions with $\mathrm{m} / \mathrm{z} 813.4^{2+}$ and $822.4^{2+}$ were formed through in-source CID, even though the ion source had been tuned to minimize fragmentation.

favor in-source dissociation of peptides, which is likely to complicate identification of cross-linked peptides.

\section{Conclusions}

Digestion of proteins cross-linked with DTSSP yields a mixture of peptides that may be modified in several different ways. To maximize the number of cross-linked residues identified, and hence the structural information, one must identify all of the ions detected. Identification of all cross-linked peptides is generally possible only when the reactivity of the cross-linking reagent and the behavior of modified peptides during analysis are known. The present study has shown that reaction of the cross-linking reagent with ammonium ions present only as an impurity in the buffer can compete effectively with hydrolysis. The present study has also shown that DTSSP may contain a substantial quantity of a reactive impurity that was formed during synthesis with a catalyst. Because DTSSP undergoes hydrolysis rapidly, chromatographic purification of DTSSP is difficult. The present study has also shown that DTSSP reacts readily with most tyrosine residues and many serine residues. While this unexpected reactivity complicates analysis of the mass spectra, it does provide the opportunity for added structural information. Lastly, the present study shows that modification of peptides with DTSSP can substantially alter their CID, which may lead to facile fragmentations in the electrospray ion source that are difficult to interpret.

Results of the present study will likely have general utility because DTSSP is just one of the several bis- $\mathrm{N}$ hydroxysuccinimidyl esters commonly used for crosslinking proteins (i.e., BS3, DSP, EGS). Furthermore, these cross-linkers follow the same mechanism for side chain modification [16], and will therefore likely react with tyrosine and serine sidechains. Our understanding of all of the major reactions of commercial DTSSP with proteins has led to development of a computer program, FragMatch, which facilitates automated analyses of the mass spectra of all peptides found in digests of proteins cross-linked with DTSSP [21].

\section{Acknowledgments}

This research was supported by grants from the National Institutes of Health (EY RO107609 and GM RO1 40384) and the Nebraska Center for Mass Spectrometry.

\section{References}

1. Young, M. M.; Tang, N.; Hempel, J. C.; Oshiro, C. M.; Taylor, E. W.; Kuntz, I. D.; Gibson, B. W.; Dollinger, G. High Throughput Protein Fold Identification by Using Experimental Constraints Derived from Intramolecular Cross-Links and Mass Spectrometry. Proc. Natl. Acad. Sci. U.S.A. 2000, 97, 5802-5806.

2. Kruppa, G. H.; Schoeniger, J.; Young, M. M. A Top Down Approach to Protein Structural Studies Using Chemical CrossLinking and Fourier Transform Mass Spectrometry. Rapid Commun. Mass Spectrom. 2003, 17, 155-162.

3. Pearson, K. M.; Pannell, L. K.; Fales, H. M. Intramolecular Cross-Linking Experiments on Cytochrome $c$ and Ribonuclease A Using an Isotope Multiplet Method. Rapid Commun. Mass Spectrom. 2002, 16, 149-159.

4. Bennett, K. L.; Kussmann, M.; Bjork, P.; Godzwon, M.; Mikkelsen, M.; Sorensen, P.; Roepstorff, P. Chemical CrossLinking with Thiol-Cleavable Reagents Combined with Differential Mass Spectometric Peptide Mapping-A Novel Approach to Assess Intermolecular Protein Contacts. Protein Sci. 2000, 9, 1503-1518.

5. Luo, Y.; Leszyk, J.; Qian, Y.; Gergely, J.; Tao, T. Residues 48 and 82 at the N-Terminal Hydrophobic Pocket of Rabbit Skeletal Muscle Troponin-C Photo-Cross-Link to Met 121 of Troponin-I. Biochemistry 1999, 38, 6678-6688.

6. Callaghan, J.; Simonsen, A.; Gaullier, J.-M.; Toh, B.-H.; Stenmark, H. The Endosome Fusion Regulator Early-Endosomal Autoantigen 1 (EEA1) is a Dimer. Biochem. J. 1999, 338, 539-543.

7. Chan, F. K.-M.; Chun, H. J.; Zheng, L.; Siegel, R. M.; Bui, K. L.; Lenardo, M. J. A Domain in TNF Receptors that Mediates Ligand-Independent Receptor Assembly and Signaling. Science 2000, 288, 2351-2354.

8. Topham, P. S.; Kawachi, H.; Haydar, S. A.; Chugh, S.; Addona, T. A.; Charron, K. B.; Holzman, L. B.; Shia, M.; Shimizu, F.; Salant, D. J. Nephritogenic mAb 5-1-6 is Directed at the Extracellular Domain of Rat Nephrin. J. Clin. Invest. 1999, 104, 1559-1566.

9. Jordan, J.; Murciano, J.; Lotero, A.; Herraez, A.; Diez, J. In Vitro Properties and Organ Uptake of Rat Band 3 Cross-Linked Erythrocytes. Biochimie 1997, 79, 53-61.

10. Ehrlich, L. S.; Agresta, B. E.; Gelfand, C. A.; Jentoft, J.; Carter, C. A. Spectral Analysis and Tryptic Susceptibility as Probes of HIV-1 Capsid Protein Structure. Virology 1994, 204, 515-525.

11. Staros, J. V. N-Hydroxylsulfosuccinimide Active Esters: Bis(Nhydroxysulfosuccinimide) Esters of Two Dicarboxylic Acids are Hydrophilic, Membrane-Impermeant, Protein Cross-Linkers. Biochemistry 1982, 21, 3950-3955.

12. Staros, J. V.; Kakkad, B. P. Cross-Linking and Chymotryptic Digestion of the Extracytoplasmic Domain of the Anion Exchange Channel in Intact Human Erythrocytes. J. Membrane Biol. 1983, 74, 247-254.

13. Lomant, A. J.; Fairbanks, G. Chemical Probes of Extended Biological Structures: Synthesis and Properties of the Cleavable Protein Cross-linking Reagent [35S]Dithiobis(succinimidyl propionate). J. Mol. Biol. 1976, 104, 243-261. 
14. Zhang, Z.; Smith, D. L.; Smith, J. B. Multiple Separations Facilitate Identification of Protein Variants by Mass Spectrometry. Proteomics 2001, 1, 1001-1009.

15. Lapko, V. N.; Jiang, X.-Y.; Smith, D. L.; Song, P.-S. Surface Topography of Phytochrome A Deduced from Specific Chemical Modification with Iodoacetamide. Biochemistry 1998, 37, 12526-12535.

16. Wong, S. S. Chemistry of Protein Conjugation and CrossLinking; CRC Press LLC: Boca Raton, FL, 1993, p 57.

17. Anjaneyulu, P. S. R.; Staros, J. V. Reactions of N-Hydroxysulfosuccinimide Active Esters. J. Peptide Protein Res. 1987, 30, 117-124.

18. Ngoka, L. C. M.; Gross, M. L. Multistep Tandem Mass Spectrometry for Sequencing Cyclic Peptides in an Ion-Trap
Mass Spectrometer. J. Am. Soc. Mass Spectrom. 1999, 10, 732-746.

19. Ngoka, L. C. M.; Gross, M. L. A Nomenclature System for Labeling Cyclic Peptide Fragments. J. Am. Soc. Mass Spectrom. 1999, 10, 360-363.

20. Maux, D.; Enjalbal, C.; Martinez, J.; Aubagnac, J.-L. New Example of Proline-Induced Fragmentation in Electrospray Ionization Mass Spectrometry. Rapid Commun. Mass Spectrom. 2002, 16, 1470-1475.

21. Wulser, K., Swaim, C., Smith, J., Smith, D. Proceedings of the 51st ASMS Conference on Mass Spectrometry and Allied Topics; Montreal, QC, Canada, June 2003. 